\title{
PENENTUAN TETAPAN KESEIMBANGAN PENJERAPAN PADA SISTEM KOLOID DENGAN METODE EKSTRAPOLASI GRAFIS
}

\author{
H. Satriadi ${ }^{*}$, I M. Bendiyasa ${ }^{* *}$ dan Rochmadi ${ }^{* *}$ )
}

\begin{abstract}
Abstrak
Percobaan penjerapan pestisida pada sistem koloid air-tanah telah mendapatkan nilai tetapan keseimbangan penjerapan yang selalu berubah dan dipengaruhi perbandingan antara berat penjerap terhadap volum pelarutnya. Hal itu terjadi karena pemisahan antara penjerap dengan pelarut sangat sulit dilakukan, dan pelarut selalu masih mengandung butir penjerap Akibatnya zat yang terjerap dalam penjerap ikut terbaca ketika menganalisis konsentrasi zat dalam pelarut. Untuk mendapatkan tetapan keseimbangan yang sebenarnya dapat dilakukan dengan modifikasi persamaan keseimbangan dan metode ekstrapolasi secara grafis Percobaan penjerapan dilakukan secara batch dengan konsentrasi awal pestisida sumithion 1,1014 ppm, perubahan konsentrasi diamati dengan kromatografi gas yang dilengkapi dengan Flame Photo Detector. Tanah yang digunakan berdiameter butir $8,066.10^{-5} \mathrm{~cm}$, diameter pori $20,443 \mathrm{~A}$, serta mengandung $2,86 \%$ bahan organik. Nilai tetapan keseimbangan sebenarnya diperoleh $123,936 \mathrm{~mL}$ air/g tanah pada $26.5^{\circ} \mathrm{C}$
\end{abstract}

Kata kunci : ekstrapolasi grafis, sistem koloid, tetapan keseimbangan penjerapan,

\section{Pendahuluan}

Tetapan keseimbangan merupakan perbandingan antara zat terjerap dalam penjerap dengan yang terlarut dalam pelarutnya. Untuk mendapatkan nilai tetapan keseimbangan, maka salah satu konsentrasi zat dalam pelarut atau yang terjerap harus dapat diketahui.

Sistem koloid terdiri atas fasa terdispersi yang berukuran sangat kecil dan mempunyai berat jenis mirip dengan fasa pendispersinya sehingga keduanya akan bercampur secara homogen, sulit dipisahkan, walaupun tidak saling melarutkan. Contoh sistem koloid adalah campuran air tanah. Pestisida yang diberikan ke tanaman sebagian akan masuk ke dalam sistem koloid air tanah, kemudian terjadi penjerapan oleh butir tanah.

Berdasarkan percobaan di laboratorium, pemisahan air dari butir tanah sangat sulit dipisahkan secara sempurna, sekalipun telah menggunakan alat sentrifus. Akibatnya, analisis konsentrasi pestisida dalam cairan sulit dilakukan, dan tetapan keseimbangan yang diperoleh nilainya dipastikan bukan yang sebenarnya (palsu). Zat pengendap tidak digunakan, karena dapat berinteraksi secara fisis maupun kimiawi dengan pestisida, serta mengganggu proses analisisnya. Proses sedimentasi tidak dilakukan mengingat umur kestabilan pestisida sangat pendek.

Dari acuan literatur dan uji laboratorium, nampak bahwa terdapat hubungan antara perbandingan (awal) berat tanah terhadap volum air pada sistem koloid dengan tetapan keseimbangan. Oleh karena itu, dengan modifikasi persamaan keseimbangan dan penggunaan metode ekstrapolasi grafis akan diperoleh nilai tetapan keseimbangan yang sesungguhnya.

\section{Dasar Teori}

Penjerapan adalah proses perpindahan zat dari fasa pelarut ke permukaan penjerap. Peristiwa tersebut terjadi karena sifat lyophobic (solvent disliking) dan gaya tarik menarik pada pembentukan ikatan antara zat terjerap dengan penjerap (Weber, 1972).

Pada peristiwa penjerapan, akan dicapai keadaan keseimbangan dinamis antara jumlah zat yang terjerap di penjerap dengan yang tertinggal dan larut dalam pelarut. Perbandingan antara keduanya dinyatakan dengan suatu nilai tetapan kesetimbangan. Bila konsentrasi zat yang terlibat pada proses penjerapan cukup kecil, maka persamaan keseimbangan dapat dinyatakan dalam bentuk linear

$$
C_{s}=K C_{l}
$$

dengan :

$$
\begin{aligned}
& C_{s}= \text { konsentrasi zat terjerap pada } \\
& \text { penjerap, mg zat terjerap/g penjerap } \\
& C_{l}= \text { konsentrasi zat terlarut dalam pelarut, } \\
& \mathrm{mg} / \mathrm{L} \text { pelarut. }
\end{aligned}
$$

\footnotetext{
*) Jurusan Teknik Kimia Fakultas Teknik, Universitas Diponegoro, Semarang

**) Jurusan Teknik Kimia Fakultas Teknik, Universitas Gajah Mada, Yogyakarta
} 


$$
K=\text { tetapan keseimbangan, (Weber,1972). }
$$

Tanah merupakan hasil pelapukan bahan induk menghasilkan komposisi organik (humus) dan anorganik (mineral tanah). Mineral tanah mengandung muatan dan berpori-pori, sedangkan humus memiliki berbagai group fungsional yang sangat reaktif mengikat berbagai zat organik (Koranto, 1991).

Pestisida adalah zat kimia pengendali populasi jasad hidup yang merugikan. Dalam air tanah, pestisida dapat mengalami penjerapan oleh butir tanah, fotolisis oleh sinar matahari, penguapan, reaksi dengan zat-zat kimia dalam tanah, serta peruraian oleh bakteri dalam tanah. (Hanindipto, 1989).

Penjerapan dalam sistem koloid. Menurut Valsaraj (1995), perbandingan awal antara penjerap dengan volum pelarut dalam sistem koloid akan berpengaruh terhadap nilai tetapan keseimbangan. a. Persamaan deferensial pestisida pada permukaan pori :

$$
\begin{aligned}
& \frac{\partial^{2} \mathrm{C}_{\mathrm{sp}}}{\partial \mathrm{r}^{2}}+\frac{2}{\mathrm{r}} \frac{\partial \mathrm{C}_{\mathrm{sp}}}{\partial \mathrm{r}}+\frac{\mathrm{K}_{\mathrm{lp}} \mathrm{a}_{\mathrm{s}}}{\mathrm{D}_{\mathrm{sp}} \rho_{\mathrm{B}}}\left(\mathrm{C}_{\mathrm{lp}}-\mathrm{C}_{\mathrm{lp}}{ }^{*}\right) \\
& =\frac{1}{\mathrm{D}_{\mathrm{sp}}} \frac{\partial \mathrm{C}_{\mathrm{sp}}}{\partial \mathrm{t}}
\end{aligned}
$$

b. Persamaan deferensial pestisida dalam cairan pori :

$$
\begin{aligned}
& \frac{\partial^{2} C_{l p}}{\partial r^{2}}+\frac{2}{r} \frac{\partial C_{l p}}{\partial r}+\frac{K_{l p} a_{s}}{\in D_{l p}}\left(C_{l p}-C_{l p}{ }^{*}\right) \\
& =\frac{1}{D_{l p}} \frac{\partial C_{l p}}{\partial t}
\end{aligned}
$$

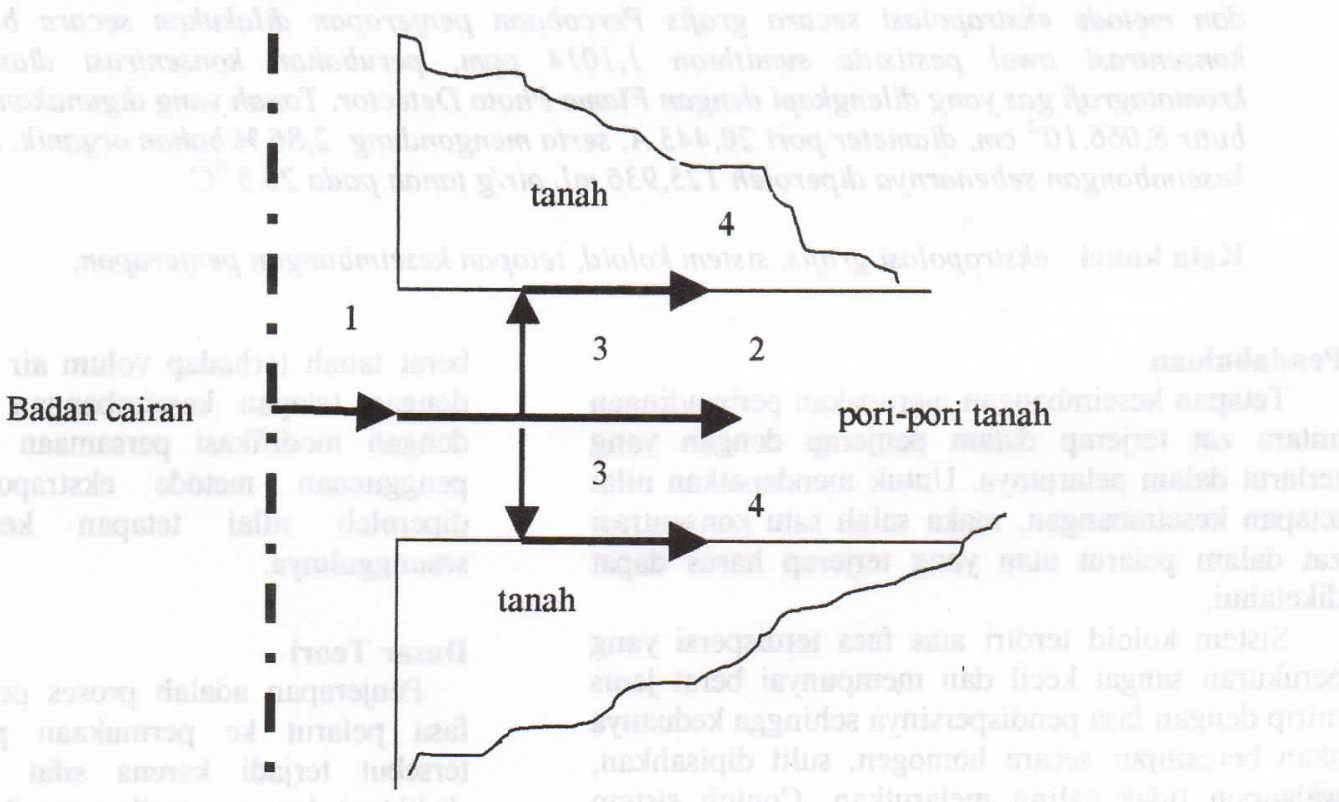

Gambar 1. Mekanisme penjerapan pada pori butir tanah

Hal ini disebabkan pemisahan yang tak sempurna antara penjerap dengan pelarut pada sistem koloid.

Peristiwa penjerapan ditinjau sampai ke dalam pori penjerap yang terdiri dari beberapa mekanisme perpindahan massa (Gambar 1):

1. Perpindahan massa dari badan cairan ke

permukaan luar butir penjerap melalui lapisan diam batas cairan- permukaan

2. Difusi dalam cairan pori

3. Perpindahan massa dari cairan pori ke permukaan pori penjerap

4. Difusi pada permukaan pori. (surface

diffusion) (Treyball, 1981).

Mekanisme ini mendasari penyusunan model matematis, dengan beberapa anggapan : butir berbentuk bola, porositas dan luas spesifik pada seluruh bagian butir homogen, difusi pada pori terjadi ke arah radial butir, dan tidak terjadi reaksi kimia. Model matematis yang tersusun terdiri atas :

c. Persamaan deferensial pestisida dalam badan cairan :

$$
\frac{\partial C l_{b}}{\partial t}=-K_{l b p} a_{s} \frac{W}{V}\left(C_{l b}-C_{l p}\right)_{r=R}
$$

(Satriadi, 1995)

Ekstrapolasi dengan metode grafis.

Berdasarkan persamaan keseimbangan (1), tetapan keseimbangan dapat dinyatakan dengan 


$$
\mathrm{K}=\frac{\mathrm{W}_{\mathrm{j}} / \mathrm{W}}{\mathrm{W}_{1} / \mathrm{V}_{\mathrm{s}}}
$$

dengan : $W_{j}=$ berat pestisida terjerap

$W=$ berat tanah penjerap

$W_{l}$ =berat pestisida terlarut

$V_{s}=$ volum suspensi air tanah

Tetapan keseimbangan dapat dinyatakan dengan dasar berat suspensi air $\operatorname{tanah} K_{W}$ :

$$
K_{W}=\frac{W_{j} / W}{W_{l} / W_{s}}
$$

dengan : $W_{s}=$ berat suspensi air tanah.

Tetapan keseimbangan dengan dasar volum air bebas koloid tanah $K^{\prime}$ adalah :

$$
K^{\prime}=\frac{W_{j} / W}{W_{l} / V}
$$

dengan : $V=$ volum air bebas koloid tanah

Nilai $K^{\prime}$ inilah yang dimaksudkan sebagai tetapan keseimbangan yang sebenarnya. Dengan persamaan (6) dan (7), dapat disusun tetapan keseimbangan dasar berat air $K_{W}^{\prime}$

$$
K_{W}^{\prime}=\frac{W_{j} / W}{W_{l} / W_{a}}
$$

dengan : $W_{a}=$ berat air

Karena berat suspensi air $\operatorname{tanah}\left(W_{s}\right)$ adalah berat air $\left(W_{a}\right)$ ditambah berat koloid tanah $\left(W_{k o l}\right)$, maka persamaan (6) dapat diubah menjadi :

$$
\begin{aligned}
K_{W} & =\frac{W_{j} / W}{W_{l} / W_{a}+W_{k o l}}=\frac{W_{a}+W_{k o l}}{W_{l}} \frac{W_{j}}{W} \\
& =\left(\frac{W_{a}}{W_{l}}+\frac{W_{k o l}}{W_{l}}\right) \frac{W_{j}}{W}
\end{aligned}
$$

persamaan dikalikan dengan $\frac{W_{a}}{W_{a}}$ diperloleh

$$
K_{W}=\left(\frac{W_{a}}{W_{l}}+\frac{W_{k o l}}{W_{a}} \frac{W_{a}}{W_{l}}\right) \frac{W_{j}}{W}
$$

Bila setelah dilakukan operasi pemizahan pada berbagai nilai awal $W N$ diperoleh hubungan linear antara $W_{k o l} W_{a}$ dengan perbandingan berat tanah mula-mula terhadap berat air, seperti ditunjukkan dengan persamaan :

$$
\frac{W_{k o l}}{W_{a}}=\psi\left(\frac{W}{V / \rho_{a}}\right)
$$

dengan : $\rho_{a}=$ rapat massa air

$$
\psi=\text { tetapan kesebandingan }
$$

Berdasarkan persamaan (10), maka persamaan (9) dapat diubah menjadi

$$
K_{w}=\left(\frac{W_{a}}{W_{l}}+\psi \frac{(W / V)}{\rho_{a}} \frac{W_{a}}{W_{l}}\right) \frac{W_{j}}{W}
$$

Dengan persamaan (8), maka persamaan (11) dapat dijadikan bentuk

$$
K_{w}=K_{w}^{\prime}+K_{w}^{\prime} \frac{\psi(W / V)}{\rho_{a}}
$$

Karena $K_{w}=\rho_{s} \cdot K \quad\left(\rho_{s}=\right.$ rapat massa suspensi tanah), dan $K_{w}^{\prime}=\rho_{a} K^{\prime}$, maka persamaan (12) dapat diubah menjadi :

$$
K \rho_{s}=K^{\prime} \rho_{a}+\psi(W / V) K^{\prime}
$$

Persamaan (13) menggambarkan hubungan antara tetapan keseimbangan yang diperoleh dari pengamatan penjerapan pada berbagai keadaan sistem koloid $K$ terhadap berbagai keadaan awal suspensi tanah $(W / V)$. Apabila dilakukan ekstrapolasi pada nilai $(W / N)$ sama dengan nol, maka akan diperoleh nilai tetapan keseimbangan sebenarnya $K^{\prime}$

\section{Percobaan}

Percobaan dilakukan secara batch, menggunakan butir-butir tanah, dan pelarut air suling. Tanah diambil dari desa Donoharjo, Kabupaten Bantul Yogyakarta, yang terlebih dahulu dianalisis sifat fisisnya, diradiasi di BATAN Jakarta agar terbebas dari bakteri pengurai pestisida. Pestisida yang digunakan ialah sumithion, jenis pestisida organofosfor, berupa cairan yang diperoleh dari Laboratorium Analisa Kimia Fisika UGM Yogyakarta. Susunan alat dapat dilihat pada gambar 2 , terdiri atas labu erlenmeyer yang diselubungi 
dengan kertas alumunium selama percobaan untuk mencegah proses fotolisis pada pestisida. Alat dilengkapi dengan pengaduk magnetik yang dilapisi teflon, serta waterbath untuk mengatur temperatur.

Mula-mula tanah direndam dengan air suling selama satu hari. Keesokan harinya ditambahkan larutan pestisida, sambil diaduk. Secara berkala diambil cuplikan campuran air tanah, dipisahkan antara air dan tanahnya dengan alat sentrifus. Cairan yang cukup bening namun masih mengandung koloid tanah tersebut diekstraksi pestisidanya dengan pelarut petroleum bensen dan dietil eter, kemudian diuapkan pelarutnya. Pestisida yang tertinggal dalam labu destilasi dilarutkan dalam aseton, selanjutnya dianalisis kadar pestisidanya menggunakan kromatografi gas yang dilengkapi dengan photo flame detector (FPD). Dari hasil percobaan diperoleh hubungan antara konsentrasi pestisida dalam air (sistem koloid) $C_{l}$ terhadap waktu $t$. Perhitungan dengan model matematis yang tersusun, serta optimasi dengan metode Hooke Jeeves (Rudd dan Watson, 1968), akhirnya diperoleh nilai tetapan keseimbangannya $K$.

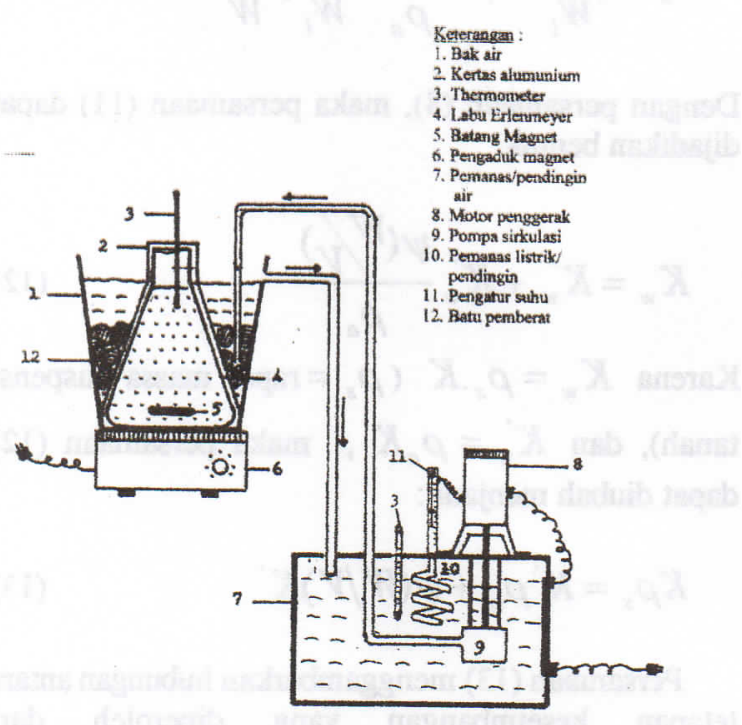

Gambar 2. Peralatan proses penjerapan pestisida pada sistem koloid air-tanah

\section{Hasil dan Pembahasan}

Hasil analisis dengan kromatografi gas FPD diperoleh hubungan antara konsentrasi pestisida dalam air $C_{l b}$ terhadap waktu percobaan $t$, pada berbagai nilai $W / V$ seperti yang terlukis pada gambar 3 . Perhitungan dengan persamaan (2), (3), (4), serta optimasi diperoleh tetapan kesetimbangan pada berbagai $W V$ sepeti pada Tabel 1.

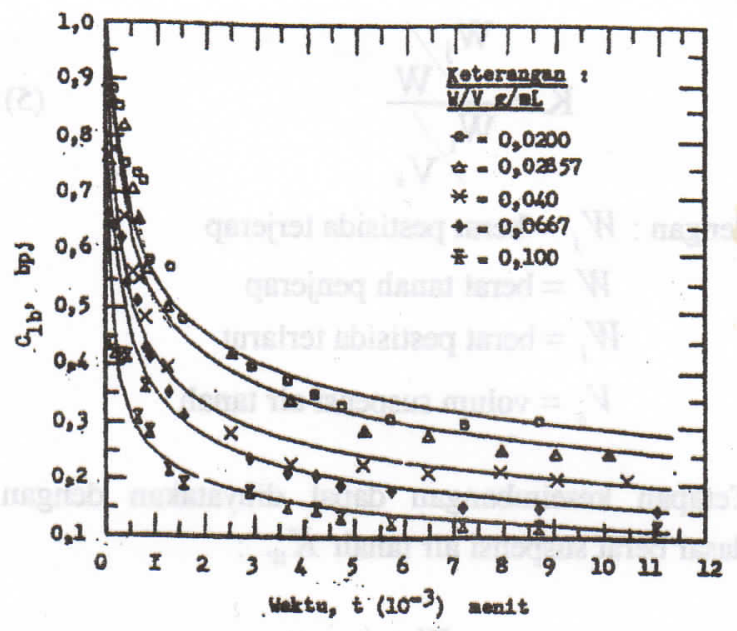

Gambar 3. Hubungan antara $C_{l b}$ terhadap $t$ pada berbagai nilai $W / V$

Tabel 1. Pengaruh $W / V$ terhadap $K$

\begin{tabular}{|l|l|l|l|l|l|}
\hline $\begin{array}{l}W / V, \\
\mathrm{~g} / \mathrm{mL}\end{array}$ & 0.0200 & 0,02857 & 0,0250 & 0,0667 & 0,1000 \\
\hline $\begin{array}{l}\mathrm{K}, \\
\mathrm{mL} / \mathrm{g}\end{array}$ & 119,485 & 103,325 & 94,493 & 75,216 & 65,879 \\
\hline
\end{tabular}

Apabila hubungan antara $W / V$ terhadap $K \rho_{s}$ diplotkan seperti pada Gambar 4 akan memben-tuk kurva yang linear. Setelah dilakukan ekstrapolasi kurva pada nilai $W / V$ sama dengan nol, maka berdasarkan persamaan (13) akan diperoleh nilai $K^{\prime} \rho_{a}$ yang merupakan intersept. Selanjutnya nilai $K$ ' dapat dihitung. Kurva linear, serta persamaannya dapat dibuat lebih baik bila menggunakan metode kuadrat terkecil (least square) yang hasilnya adalah sebagai berikut :

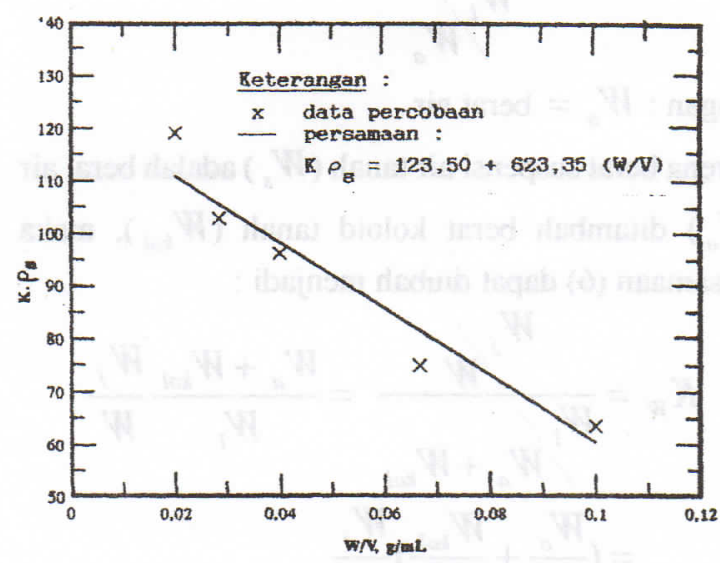

Gambar 4. Hubungan antara $K \rho_{s}$ dan $W / V$ 


$$
K \rho_{s}=123,50+623,345(W / V)
$$

Berdasarkan persamaan (13), maka nilai $K \rho_{a}$ adalah $123,50 \mathrm{~g}$ air/g tanah. Karena rapat massa air $0.9965 \mathrm{~g} / \mathrm{ml}$, maka $\mathrm{K}$ ' sama dengan $123,936 \mathrm{ml}$ air/g tanah.

\section{Kesimpulan}

Dari hasil penelitian dan pembahasan dapat disimpulkan :

1. Terdapat hubungan antara perbandingan antara berat tanah dan volum air $W N$ terhadap tetapan keseimbangan penjerapan $K$.

2. Nilai tetapan keseimbangan yang sebenarnya dapat dicari menggunakan metode ekstrapolasi pada nilai W/V sama dengan nol.

3.Nilai tetapan keseimbangan penjerapan pestisida sumithion pada sistem air-tanah sebesar 123,936 $\mathrm{ml}$ air/g tanah.

\section{Ucapan Terimakasih}

Penyusun menyampaikan terimakasih kepada proyek penelitian dan team URGE Batch I 1995, Laboratorium OTK Jurusan Teknik Kimia UGM dan Labortorium Analisa Kimia Fisika UGM

\section{Daftar Notasi}

$C_{l b} \quad$ konsentrasi pestisida dalam badan cairan

$C_{l p}$ konsentrasi pestisida dalam cairan pori

$C_{s p} \quad$ konsentrasi pestisida pada permukaan pori

$D_{s p} \quad$ tetapan difusi efektif pada permukaan pori

$D_{l p} \quad$ tetapan difusi efektif dalam cairan pori

$K_{l p} a_{s}$ tetapan perpindahan massa antar fasa cairpadat

$K_{l b p} a_{b}$ tetapan perpindahan massa dari badan cairan ke cairan pori

$\in$ perbandingan volum pori terhadap volum butir

$\rho_{B} \quad$ rapat massa butir tanah $b, \mathrm{~g} / \mathrm{mL}$

$r \quad$ jarak arah jari-jari butir

\section{Daftar Pustaka}

Hanindipto, W.D., (1989), "Kajian Penggunaan Pestisida Terhadap Kelestarian Kemampuan Lingkungan I Kabupaten Dati II Klaten ", Master Tesis Pasca Sarjana, UGM, Yogyakarta.

Hantoro Satriadi, (1998), "Penjerapan Pestisida Organoafosfor Dalam Air Oleh Tanah Secara Batch", Master Thesis, Program Pasca Sarjana, UGM.

Koranto,C.A.D., (1991), "Ilmu Tanah", Fakultas Pertanian UGM,Yogyakarta, hal. 15.

Rudd, .F. and Watson, C.C., (1968), "Strategy of Process Engineering", John Wiley and Sons, New York, pp.170-172.

Treyball, R.E., (1981), "Mass Transfer Operation", 3 ed., McGraw Hill International Book Company, Tokyo, pp 565.

Valsaraj, K.T., (1995), "Termodynamics and Kinetics", Lewis Publisher, New York pp. 78-93.

Warkentin, B.P., Young,R.N., and Mohamed A.M.O., (1992), "Principles of Contaminants Transport in Solid", Elsevier Science Publisher, Amsterdam, pp. 240-245

Weber, J.R.,1972, "Physicochemical Processes for Water Quality Control", Wiley Interscience, New York. pp. 199 